\title{
COMPARISON OF THE LQG AND H-INFINITY TECHNIQUES TO DESIGN EXPERIMENTALLY A FLEXIBLE SATELLITE ATTITUDE CONTROL SYSTEM
}

\author{
J. V. C. de Castro \\ University of Minas Gerais, Mechanical Engineering Department \\ Rua Espírito Santos, 35, Belo Horizonte, MG, Brasil. \\ email: joaocarlosvilela@gmail.com
}

\section{C. G. de Souza}

\begin{abstract}
National Institute for Space Research, Space Mechanics and Control Division Av. dos Astronautas, 1758, S J dos Campos, SP, Brasil email: lcgadelha@gmail.com or gadelha@dem.inpe.br
\end{abstract}

\begin{abstract}
Attitude Control System (ACS) for flexible space satellites demands great reliability, autonomy and robustness. These flexible structures face low stiffness due to minimal mass weight requirements. Satellite ACS design usually based on computer simulations without experimental verification can face instability and/or inefficient controller performance due to model uncertainties. In this paper one investigates the robustness and performance of the time domain approach $L Q G$ (Lineal Quadratic Gaussian) and the frequency domain $H_{-}$ Infinity approach. The satellite ACS design is performed initially in a computer simulation environment, following experimentally verification of the same control algorithm, using Quanser rotary flexible link module. This investigation has shown that the controller performance based on simulation model can be degraded when applied in an experimental set up. So this prototype verification is fundamental before satellite onboard computer algorithms implementation.
\end{abstract}

\section{Introduction}

There are several methodologies to investigate the satellite ACS performance, depending on the investigation objectives; computer simulation cannot be the appropriate one. The use of experimental platforms has the important advantage of allowing the satellite dynamics representation in laboratory, from which is possible to accomplish experiments and simulations to evaluate satellites ACS. Experimental test has also the possibility of introducing more realism than the simulation, however, it has the difficulty of reproducing zero gravity and torque free space condition. Examples of experimental platforms for investigating different aspects of the satellite dynamic and control system can be found in Hall et al.(2002) and Berry et al.(2003). A classic case of a phenomenon that was not investigated experimentally before launch, was the dissipation energy effect that has altered the satellite Explorer I rotation Kaplam (1976). Several institutes and universities Tsiotras et al.(2007) are investigating and testing the ACS performance through prototypes. The great difficult in experimental test of equipment and/or control techniques is to reproduce all the space characteristics on Earth Prado et al.(2005). An important aspect that must be first identified through experimental procedure is the platform inertia parameters Conti (2006). An attempt to simulate such an environment on Earth can be done by air bearings, which provide an environment nearly torque free, perhaps as close as possible to the space, which makes this setup a preferred technology to investigate the attitude dynamics and control system Schwartz et al.(2003). An experimental apparatus was used in Dichmann and Sedlak (1998) and Cannon and Rosenthal (1984) to investigate the dynamics and the control laws for a satellite composed of rigid and flexible parts. The influence of the nonlinearity introduced by the panel's flexibility in the parameters variation, indicating the need of robust controller was investigated in Souza (1992). The controller obtained in Holub (2005) for a rigid-flexible structure was designed using the H-infinity technique for a Very Large Telescope (VLT), located in Chile. The order of the controller obtained was one disadvantage in comparison to others controllers, implying in the application of a method for reducing the controller order. The H-infinity controller was tested experimentally using the Rotary Flexible link Quanser@ Flexgage equipment Quanser homepage. A method for controlling a flexible structure using a bang-bang controller with the goal of minimizing the time and the residual energy of the flexible modes was done by Albassam (2004). The vibration modes was eliminated by placing a concentrated mass along the flexible appendage, changing the dynamics of the system and ensuring that the control does not excite the flexible modes of the structure. Numerical simulations and experiments showing the efficiency of the proposed control method have been done. Another interesting work, using the Quanser@ equipment was done by Barbosa and Góes (2007), which uses a flexible framework for studying the movement of liquid propellants in rocket motors, assuming that the dynamic behavior the structure and fluid are similar. The digital controller designed based on Compensed Inverse PID (CIPID) technique combines three individual controllers in parallel, tuned to the frequencies of the flexible modes. The system was implemented in a Quanser@ Rotary Flexible Link System 
also, the CIPID controller performance was compared to a simple proportional controller. In Souza (1996) it was showed that the influence of the non-linearities introduced by the panel's flexibility and the system parameters variation can degrade the control system performance, indicating the necessity of new robust control technique. In this paper one investigates and compare experimentally the robustness and performance of two different multivariable methodologies in designing the ACS for a rigid-flexible satellite, using Quanser rotary flexible link module. The first one is the traditional time domain approach LQG (Lineal Quadratic Gaussian) and the second one is the frequency domain H-Infinity approach Skogestad and Postlethwaite (2005). This preliminary investigation has shown that the controller performance based on the simulation model can be degraded when applied in an experimental setup Conti and Souza (2008). Besides, these results have shown that the H-infinity controller has the disadvantages of having superior order than the plant, although it can be robust against uncertainties like the nonlinearties of the model Gonzales and Souza (2009), since it takes into account all sources of uncertainties in the controller design.

\section{Rigid flexible satellite model}

The satellite model consists of a central rigid part clamped to a thin flexible link and the output is an analog signal proportional to the deflection of the link. The experimental set up used is the Quanser rotary servo plant resulting in a horizontally rotating flexible link to perform rigid flexible control. This system is similar in nature to the control problems encountered in large light space structures where the weight constraints result in flexible structures that must be controlled using feedback techniques. A DC motor rotates the flexible link from one end in the horizontal plane. The motor of the link is instrumented with a strain gage that can detect the deflection of the tip. Fig. 1 shows the flexible link at a given rotation angle $\theta$ resulting in the arm end-point displacement D with the flexible link deflection $\alpha=\mathrm{D} / \mathrm{L}$. Table 1 shows the list of parameters and variables used in the derivation of the state-space equations of the system.

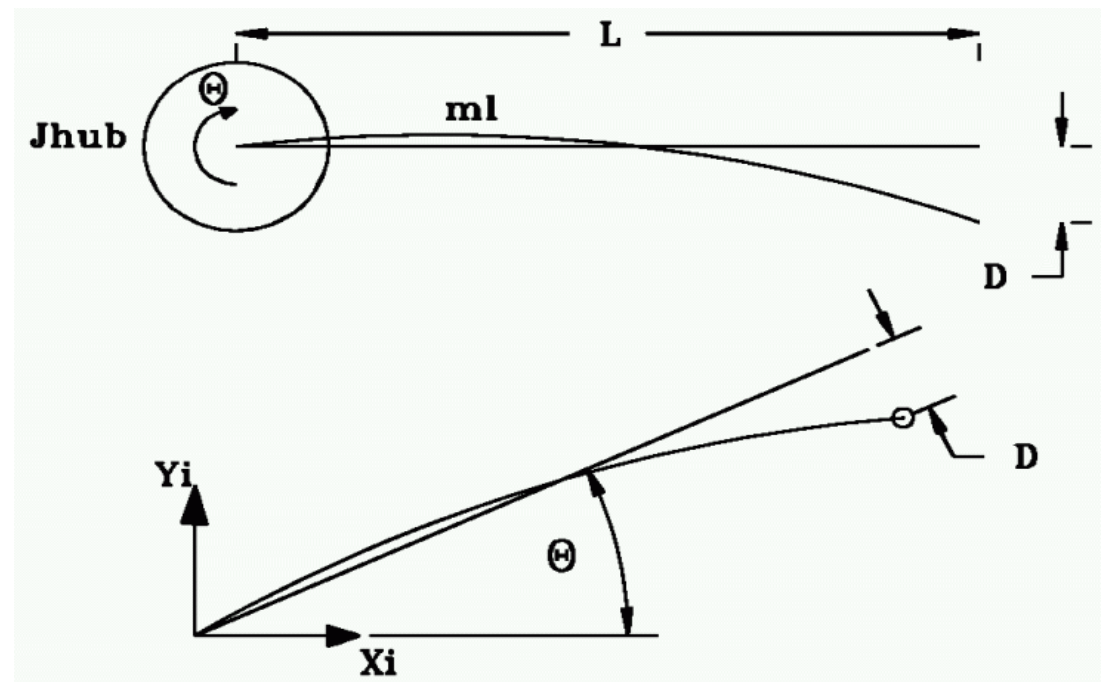

Figure 1. Flexible Link with the rigid rotation and flexible deflection

Table 1. Parameters and variables used in the derivation of the system equations of motions

\begin{tabular}{|l|l|}
\hline Symbol & Description \\
\hline$L$ & Length of flexible Link \\
\hline$m$ & Mass of flexible Link \\
\hline$K_{-}$Gage & Strain Gage Calibration factor \\
\hline$\theta$ & Servo load gear angle (radians) \\
\hline$\alpha$ & Arm Deflection (radians) \\
\hline$D$ & Link End-point Deflection \\
\hline$\omega_{c}$ & Link Damped Natural Frequency \\
\hline$I_{\text {Link }}$ & Link Moment of inertia \\
\hline Jhub & Hub Moment of inertia \\
\hline
\end{tabular}




\section{Equations of motions}

Considering a simple mass spring model for the flexible link, the rotary spring equations of motion is given by

$$
J_{\text {LINK }} \ddot{\alpha}=-K_{\text {STIFF }} \alpha
$$

where $K_{\text {stiff }}$ is the link stiffness that is related to flexible link deflection $\alpha$ and the link's damped natural frequency by

$$
\ddot{\alpha}=-\omega_{c}^{2} \alpha
$$

Combining equations (1) and (1), one obtains

$$
K_{\text {STIFF }}=\omega_{c}^{2} J_{\text {LINK }}
$$

The system equations of motion are obtained using Lagrange formulation Souza (1996), from the Kinetic and Potential energies of the system. As a result, the Lagrangian function given by

$$
L=T-V=\frac{J_{e q} \dot{\theta}^{2}}{2}+\frac{J_{L I N K}(\dot{\theta}+\dot{\alpha})^{2}}{2}-\frac{K_{\text {STIFF }} \alpha^{2}}{2}
$$

Applying the Lagrange formulation for the generalized coordinates $\theta$ and $\alpha$ one obtains the two equations of motions

$$
\begin{aligned}
& J_{e q} \ddot{\theta}+J_{A R M}(\ddot{\theta}+\ddot{\alpha})=T_{\text {OUTPUT }}-B_{e q} \dot{\theta} \\
& J_{A R M}(\dot{\theta}+\dot{\alpha})+K_{\text {STIFF }} \alpha=0
\end{aligned}
$$

where the output torque on the load from the motor is given by

$$
T_{\text {OUTPUT }}=\frac{\eta_{m} \eta_{g} K_{T} K_{g}\left(V_{m}-K_{g} K_{m}\right) \dot{\theta}}{R_{m}}
$$

Combining equations (5), (6) and (7), one obtains the complete system state-space equations of motion given by

$$
\left[\begin{array}{c}
\dot{\theta} \\
\dot{\alpha} \\
\ddot{\theta} \\
\ddot{\alpha}
\end{array}\right]=\left[\begin{array}{cccc}
0 & 0 & 1 & 0 \\
0 & 0 & \frac{-\eta_{m} \eta_{g} K_{T} K_{m} K_{g}^{2}+B_{e q} R_{m}}{J_{e q} R_{m}} & 0 \\
0 & \frac{K_{S T I F F}}{J_{e q}} & \frac{\eta_{m} \eta_{g} K_{T} K_{m} K_{g}^{2}+B_{e q} R_{m}}{J_{e q} R_{m}} & 0 \\
0 & \frac{-K_{\text {STIFF }}\left(J_{e q}+J_{A R M}\right)}{J_{e q} J_{A R M}} & \frac{\eta^{2}}{0}
\end{array}\right]+\left[\begin{array}{c}
\theta \\
\alpha \\
\dot{\theta} \\
\dot{\alpha}
\end{array}\right]+\left[\begin{array}{c}
0 \\
\frac{\eta_{m} \eta_{g} K_{T} K_{g}}{J_{e q} R_{m}} \\
-\eta_{m} \eta_{g} K_{T} K_{g} \\
J_{e q} R_{m}
\end{array}\right] V_{m}
$$

Where $\eta_{m}$ and $\eta_{g}$ are the motor and gearbox efficiencies, $K_{T}$ and $K_{g}$ are transmission and motor rate. $R_{m}$ is the armature resistance, $\mathrm{V}_{\mathrm{m}}$ the armature input voltage, $\mathrm{K}_{\mathrm{m}}$ the back-emf constant and $\mathrm{J}_{\text {eq }}$ the equivalent moment of inertia at the load. Details of this derivation can be found in Quanser Manual Quanser homepage.

\section{The LQG method}

Considers the state estimation problem of a stochastic system given by

$$
\begin{aligned}
& \dot{x}(t)=A x(t)+B u(t)+G w(t) \\
& y(t)=C x(t)+v(t)
\end{aligned}
$$


where $\mathrm{w}(\mathrm{t})$ and $\mathrm{v}(\mathrm{t})$ are Gaussian noises with mean zero and having covariance's

$$
\mathrm{E}\left\{\mathrm{w}(\mathrm{t}) \mathrm{w}^{\prime}(\mathrm{t})\right\}=\mathrm{W} \geq 0, \mathrm{E}\left\{\mathrm{v}(\mathrm{t}) \mathrm{v}^{\prime}(\mathrm{t})\right\}=\mathrm{V}>0, E\left\{w(t) v^{\prime}(t)\right\}=0
$$

The input $\mathrm{u}(\mathrm{t})$ represents the control vector, $\mathrm{y}(\mathrm{t})$ the vector of measured outputs, $\mathrm{w}(\mathrm{t})$ and $\mathrm{v}(\mathrm{t})$ are the system and measures noise, respectively.

The solution of the LQG problem consists in obtained a feedback control law that minimizes the cost

$$
J=\lim E\left\{\int_{0}^{\infty}\left(x^{\prime}(t) Q x(t)+u^{\prime}(t) \operatorname{Ru}(t)\right) d t\right\}
$$

By the separation principle, the solution of the LQG problem reduces to two sub-problem Souza (1996). The first one is the LQR problem which aims at to design an optimal control law $\mathrm{u}$, such that, minimizes the deterministic cost given by

$$
J=\int_{0}^{\infty}\left(x^{\prime}(t) Q x(t)+u^{\prime}(t) R u(t)\right) d t
$$

where the matrices $\mathrm{Q}$ and $\mathrm{R}$ are semi-positive and positive defined, respectively. The system is represented by

$$
\dot{\mathrm{x}}(\mathrm{t})=\mathrm{Ax}(\mathrm{t})+\mathrm{Bu}(\mathrm{t})
$$

and the control law is defined by

$$
\mathrm{u}=-\mathrm{K}_{\mathrm{r}}(\mathrm{t}) \mathrm{x}(\mathrm{t})
$$

with the gain $\mathrm{K}(\mathrm{t})$ is given by

$$
\mathrm{K}_{\mathrm{r}}=\mathrm{R}^{-1} \mathrm{~B}^{\prime} \mathrm{P}(\mathrm{t})
$$

and $\mathrm{P}(\mathrm{t})$ is the solution of Riccati equation

$$
-\dot{\mathrm{P}}=\mathrm{A}^{\prime} \mathrm{P}+\mathrm{PA}+\mathrm{Q}-\mathrm{PBR}^{-1} \mathrm{~B}^{\prime} \mathrm{P}
$$

In the stationary case, the Riccati equation is equal to zero. The LQR approach assumes that the system dynamic is perfect, there are no disturbances, and all states are available to feedback, a hypothesis that does not occur in the majority of the application.

The second one is the Kalman Filter problem given by a state estimator of the form

$$
\dot{\hat{x}}(\mathrm{t})=\left(\mathrm{A}-\mathrm{K}_{\mathrm{f}} \mathrm{C}\right) \hat{\mathrm{x}}(\mathrm{t})+\mathrm{Bu}(\mathrm{t})+\mathrm{K}_{\mathrm{f}} \mathrm{y}
$$

with the control law $\mathrm{u}=-\mathrm{K}_{\mathrm{r}} \hat{\mathrm{X}}$ based on the estate estimated vectors $\hat{\mathrm{X}}$, and the Kalman filter gain is given by

$$
\mathrm{K}_{\mathrm{F}}=\mathrm{P}_{\mathrm{K}} \mathrm{C}^{\mathrm{T}} \mathrm{V}^{-1}
$$

where $\mathrm{P}_{\mathrm{K}}$ satisfies another algebraic Riccati equation

$$
0=\mathrm{AP}_{\mathrm{K}}+\mathrm{P}_{\mathrm{K}} \mathrm{A}^{\prime}+\mathrm{GWG}-\mathrm{P}_{\mathrm{K}} \mathrm{C}^{\prime} \mathrm{V}^{-1} \mathrm{CP}_{\mathrm{K}}
$$

From the design perceptive one has to find a compensator with a structure that is a series connection of the LQR and KF problems as shown in Fig. 2, where G(s) is the plant of the system. It is very well knows that the LQR and Kalman filter have very good robustness and performance properties when are designed separately. However, this is not the case for the LQG compensator Souza (1996). 


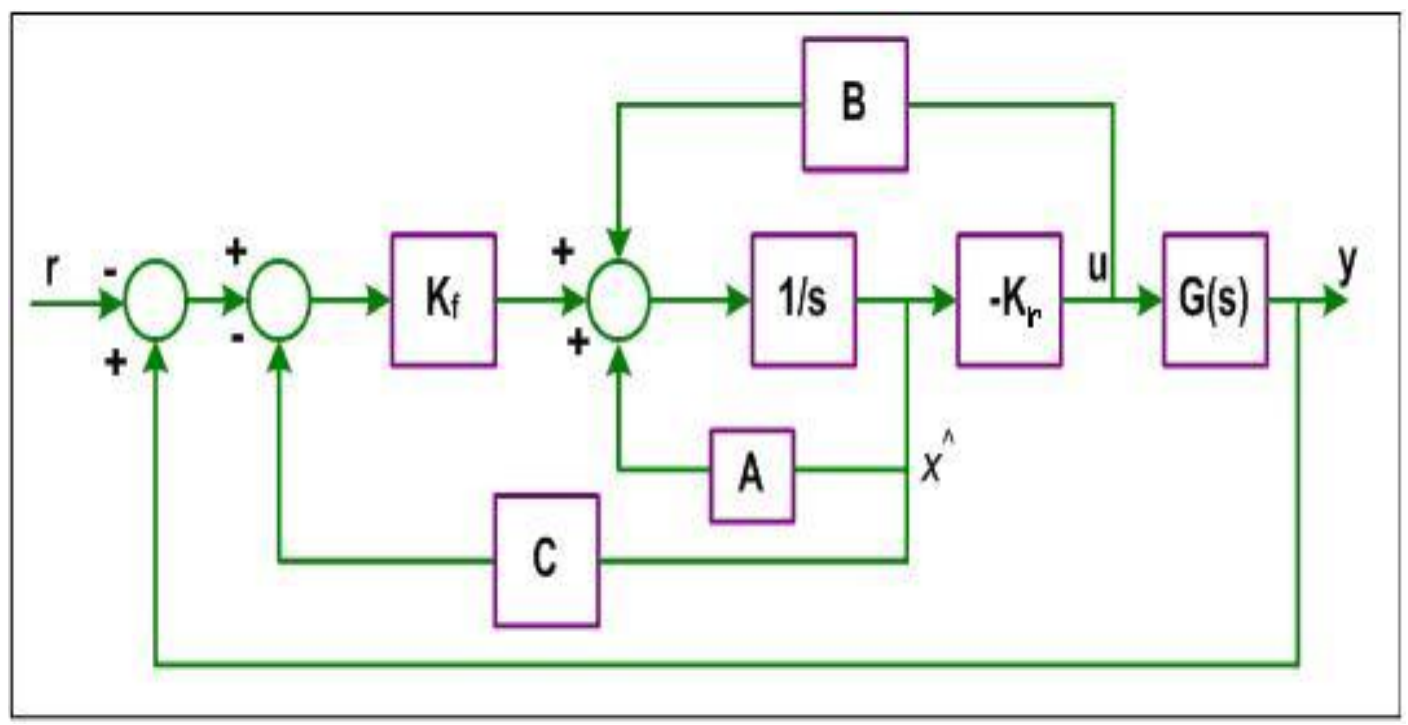

Figure 2. Series connection of the LQG Controller Structure

\section{The H-infinity method}

The Ho control theory Skogestad and Postlethwaite (2005) combines concepts of the time and frequency domain in order to give a unified solution. Its advantage is the ability to include in the solution of optimization problem requirements of performance as bandwidth, time of response and minimization of the cost function. Fig. 3, shows a general configuration of the $\mathrm{H} \infty$ method, where the signal w represents the entries outside the system, $\mathrm{z}$ is the signal error, composed of all those signals needed to characterize the behavior of the closed loop system, $u$ is the sign of control, and e is the sign of difference between the exit y and entries w. The problem of control is to determine a gain $\mathrm{K}$ that stabilize the plant $\mathrm{G}$ and minimize the transfer functions between $\mathrm{w}$ and $\mathrm{z}$.

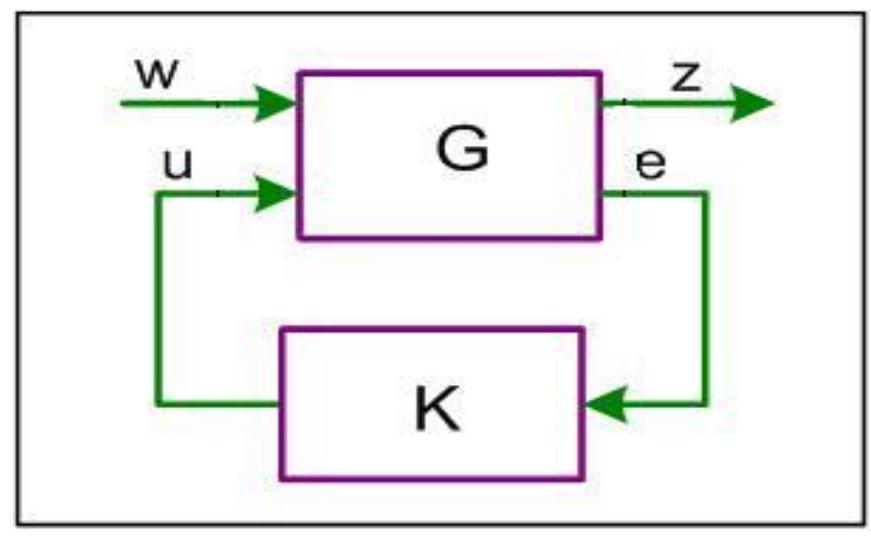

Figure 3. General Configuration of $\mathbf{H} \infty$ method

The Hळo controller is base on the state space system

$$
\begin{aligned}
& \dot{x}=A x+B u \\
& y=C x+D u
\end{aligned}
$$

which in more details is given by

$$
\left[\begin{array}{l}
x(t) \\
z(t) \\
y(t)
\end{array}\right]=\left[\begin{array}{ccc}
A & B_{1} & B_{2} \\
C_{1} & D_{11} & D_{12} \\
C_{2} & D_{21} & D_{22}
\end{array}\right] \cdot\left[\begin{array}{l}
x(t) \\
w(t) \\
u(t)
\end{array}\right]
$$


Figure 4 shows that the plant is formed with the weight $\mathrm{W}_{1}, \mathrm{~W}_{2}$ and $\mathrm{W}_{3}$. In the design controller good performance and robustness are function of the weight, so as, $\mathrm{z}_{1}=\mathrm{W}_{1} \mathrm{e} ; \mathrm{z}_{2}=\mathrm{W}_{2} \mathrm{y}$ and $\mathrm{z}_{3}=\mathrm{W}_{3} \mathrm{u}$.

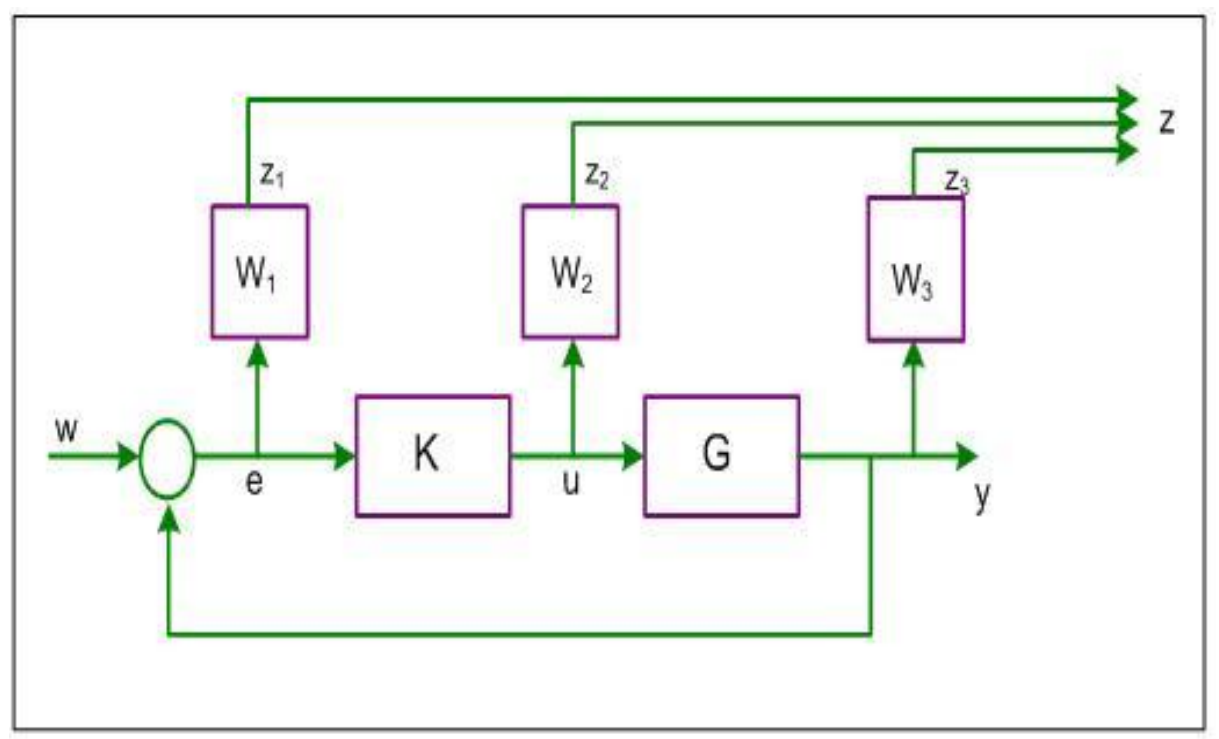

Figure 4. Augmented plant with the weight used in the $H \infty$ controller design

In the H-infinity controller design the central tuning parameter is the mixed sensibility function given by

$$
N_{y 1 u 1}=\left[\begin{array}{c}
W_{1} S \\
W_{2} R \\
W_{3} T
\end{array}\right] \quad \begin{gathered}
S=(I+G K)^{-1} \\
R=K(I+G K)^{-1} \\
T=G K(I+G K)^{-1}
\end{gathered}
$$

where $S$ is the sensibility function, T complementary sensibility function and R is the energy function. The mixed sensibility function has the property of penalizing at the same time $\mathrm{S}, \mathrm{R}$ and $\mathrm{T}$, which are treated as project requirements. From Fig. 5 one observes that transfer function from $w$ to $z_{1}$ is the sensitivity function $\mathrm{W}_{1} \mathrm{~S}$, associated to the performance of tracking putting a lower limit on the bandwidth of the closed loop system. The transfer function from $\mathrm{w}$ to $\mathrm{z}_{2}$ is the function $\mathrm{W}_{2} \mathrm{R}$, associated to the control energy and the transfer function from $\mathrm{w}$ to $\mathrm{z}_{3}$ is the function $\mathrm{W}_{3} \mathrm{~T}$, which minimize low gains at high frequencies.

\section{Simulation and experimental results}

The performance of the LQR, LQG and H-infinity controllers designed by simulation program and implemented in the Quanser flexible link experiment are presented. The controller performance is evaluated in controlling rigid motion, damping the flexible displacement, and following a reference input of $30^{\circ}$. The outputs are measurements by angular and flexible displacement sensors, tachometers and strains gage, respectively. The controls laws define the voltage $\mathrm{V}_{\mathrm{m}}$ over the DC motor. The gains used experimentally are those obtained for best performance case in the computer simulation. In order to run the experiment in real time, one builds a Matlab simulink program and converts they to $\mathrm{C}$ language, using WinCon software algorithms Quanser homepage. One knows that the flexible link device is subject to noises due to sensors and no modeled dynamics (effects of the wire connecting the flexible arm, damping coefficients in the motor and reduction of the flexible model). However, in the controller design by computer one considers only the sensors noise. Due to experiment construction there is dead zone energy limits so as the DC motor has thresholds of $+/-0.2 \mathrm{~V}$. The complete Quanser flexible link setup is showed in Fig. 5. 


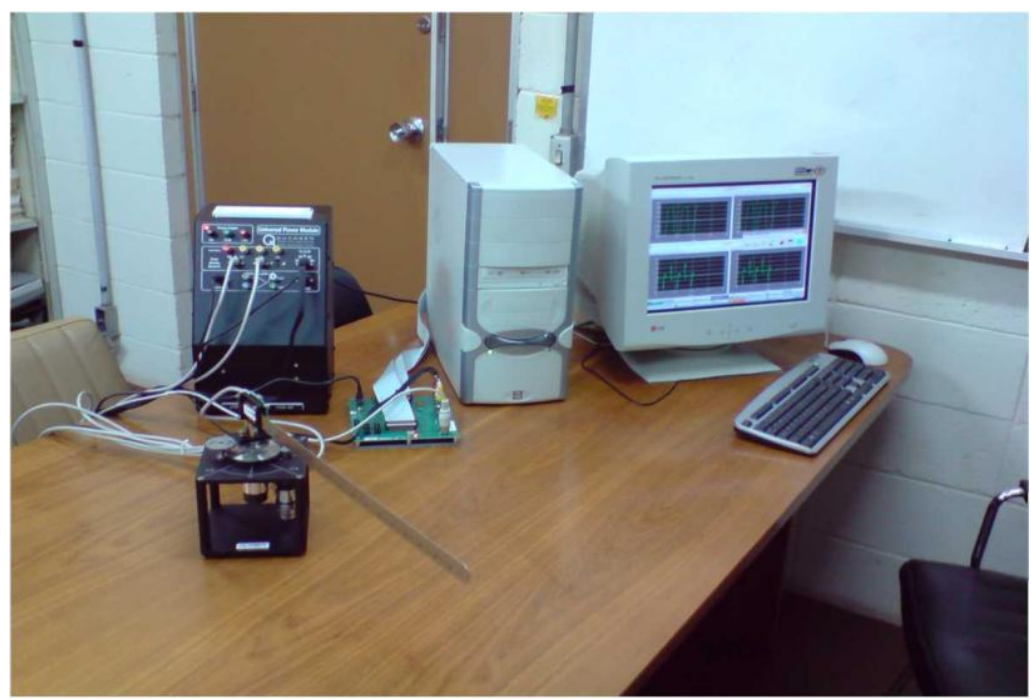

Figure 5. Complete Quanser flexible link set up used to run real time algorithms

The three controllers LQR, LQG and $\mathrm{H}_{\mathrm{oo}}$ control performance are shown in fig. 6, for the angular rigid body displacement (a), the flexible displacement (b) and the sun of both (c). One observes that the three controllers present a quick response, however, the stead state error for rigid body motion is not totally eliminated. As for this requirement the $\mathrm{H}_{\mathrm{oo}}$ controller presents inferior performance than the LQR e LQG controllers. Concerning the vibration control the $\mathrm{H}_{\mathrm{oo}}$ controller presents bigger overshot than the LQR e LQG controllers, which has a very similar behaviour.

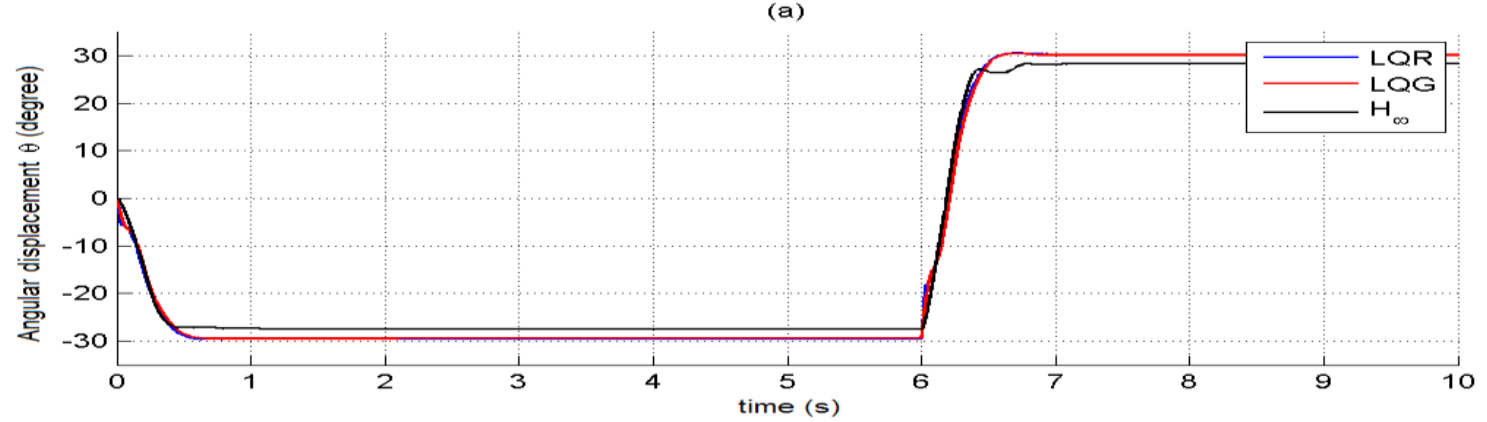

(b)

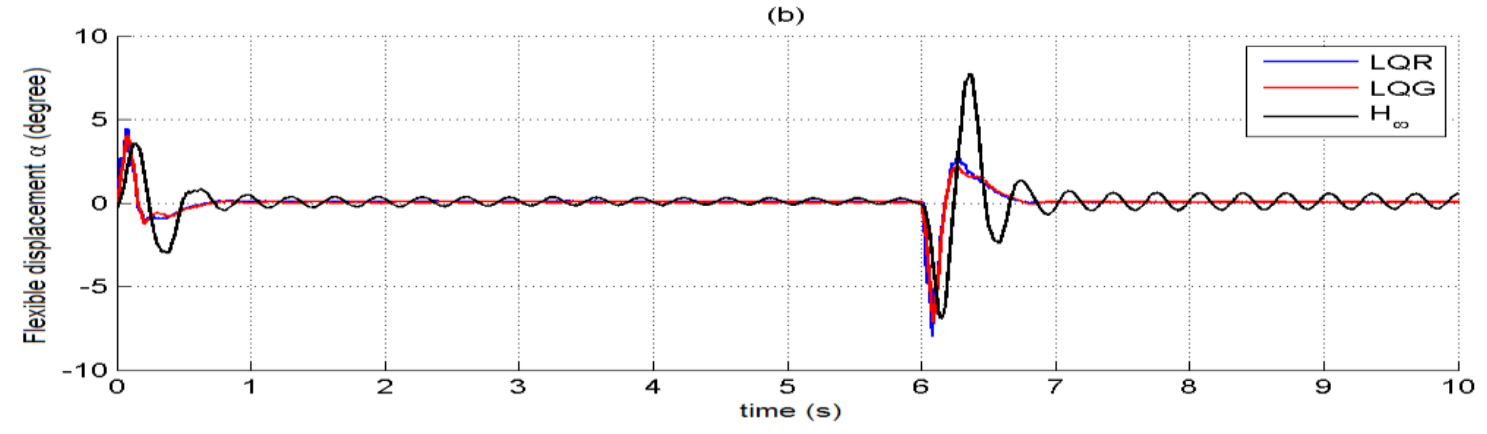

(c)

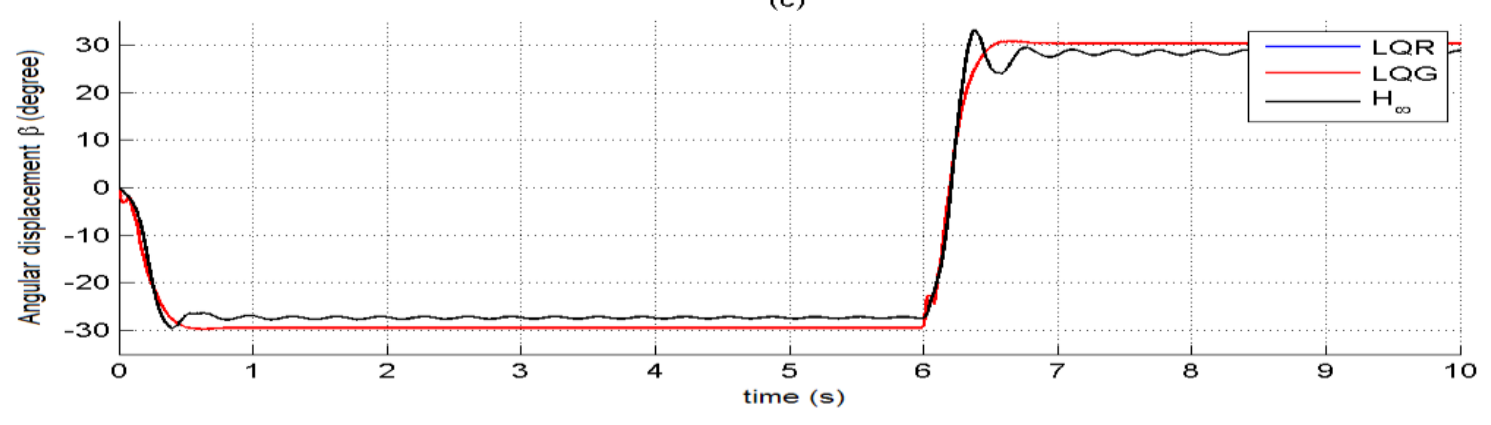

Figure 6. Controllers' performance for rigid (a), flexible (b) and the sun (c) motions 
The $\mathrm{H}_{\mathrm{oo}}$ controller poor performance can be associated to the no modelled dynamics of the plant, since this source of uncertainty was not considered in the computer controller design. In the experimental apparatus there is a lot of this kind of uncertainty, due to the wire connections. This behaves also shows that the $\mathrm{H}_{\mathrm{oo}}$ controller is more sensitive than LQR and LQG controllers. However, as for energy limit, fig. 7 shows that the $\mathrm{H}_{\mathrm{oo}}$ controller has superior experimental performance than the LQR and LQG controller, since the LQR and LQG peaks are greater than the $\mathrm{H}_{\mathrm{oo}}$ controller. Finally, it is important to say that the three controllers are function of they tuning weight matrices, which once better designed will improve these controller performances.

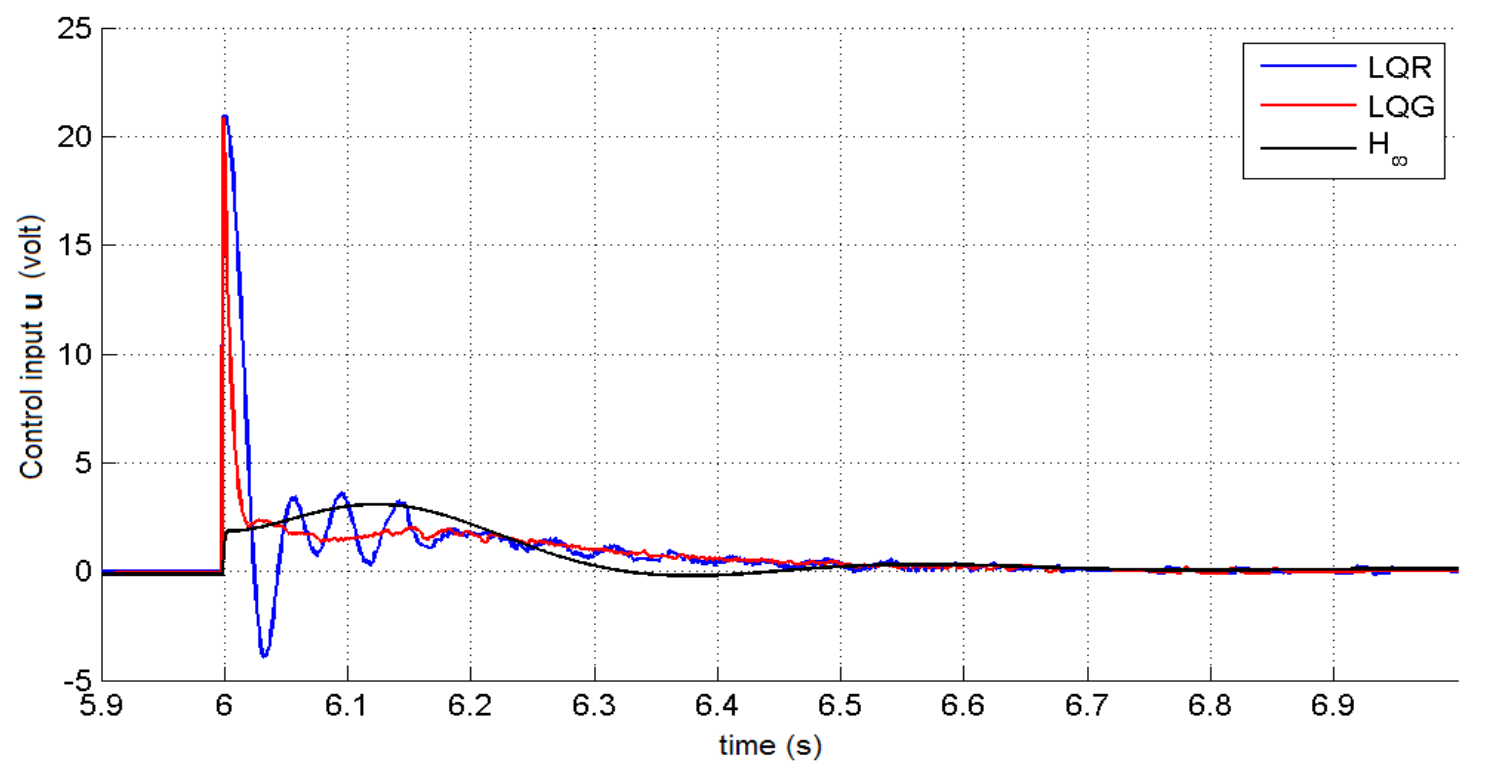

Figure 7. Controllers' performance in terns of energy limits

The performance difference between the computer controller design and experimentally implementation was also associated to the integration time. Because, in computer simulation design the integration algorithms were better and more precise, with the possibility of using variable time steps, while in the experimental implementation the time steps were restrict to the sample time of $1 \mathrm{Khz}$ for construction reasons. Another problem that could affect the controller performance was that the $\mathrm{H}_{\mathrm{oo}}$ controller gain $\left(\mathrm{K}_{\mathrm{Hoo}}\right)$ was a transfer function of high order, consequently, demanding more process time than the LQR and LQG controller, since the gains of both were constant matrix.

\section{Summary and conclusions}

In this work one investigates the dynamics and design of an ACS for the Quanser rigid flexible link experiment. This model allows studying problems associated to rigid flexible space structures, like flexible solar panels and solar sail with rigid flexible coupled motions. The Lagrange methodology was used to derive the rigid flexible link set up equations of motion, considering the device was a simple spring mass model. From this model one designs and investigates three controllers performance using the LQR, LQG e $\mathrm{H}_{00}$ technique. Initially one designs the controller by computer simulation following a real time experimental implementation using the Quanser rigid flexible link set up. Experimentally one observes that all three controllers have good performance with its pros and contras. The LQR controller design is simple and robust but it does not consider the system noise, besides it needs all the states to be feedback. The LQG controller is more realists since it takes into account the system noise and permits to estimate the states that are not available by the Kalman filter procedure. As a consequence, the LQG controller is less robust than the LQR, mainly as for the system uncertainty. The $\mathrm{H}_{00}$ controller has the great advantages of taking into account in the design, the sensibility function $\mathrm{S}$, complementary sensibility function $\mathrm{T}$ and $\mathrm{R}$ that are function associated to performance, robustness and energy limit. In the H00 design one must to minimize the mixed sensibility function $\mathrm{N}$ according to the project requirements associated to quick time response to control rigid and flexible displacements, good tracking and small controller energy limits. Although, the H0O method comprises performance and robustness, its has the disadvantage of being of high order than the plant, which can difficult its on board computer implementation. 


\section{References}

B., A., Albassam, Fast maneuver control design for flexible structures using concentrated masses. Journal of Sound and Vibration, 273, (2004), 755-775.

C., D., Hall, P., Tsiotras, H., Shen., Tracking Rigid Body Motion Using Thrusters and Momentum Wheels, Journal of the Astronautical Sciences, 2002.

D., Dichmann, J., Sedlak, Test of a Flexible Spacecraft Dynamics Simulator. Published by AAS in Advances in the Astronautical Sciences, 100, I, (1998), 501-526. Paper AAS 98-340.

E., G., Barbosa, L., C., S., Góes, Flexible structure control and validation using Flexgage Quanser system. In ABCM. 19th International Congress of Mechanical Engineering. Brasília, DF, Brasil, 2007.

G., T., Conti, L., C., G., Souza, Satellite attitude control system simulator. Journal of Sound and vibration. 15, 3-4, (2008), 395-402.

G., T., F, Conti, Satellite Attitude Control System Simulator. Proceedings of the National Institute for Space Research Seminar - SICINPE, August, Brasil, 2006.

J., L., Schwartz, M., A., Peck, C., D., Hall, Historical review of air-bearing spacecraft simulators. Journal of Guidance, Control and Dynamics, 26, 4, (2003),513-522.

J., Prado, G., Bisiacchi, L., Reyes, E., Vicente, F., Contreres, M., Mesinas, A., Juares, Three-axis airbearing based platform for small satellite attitude determination and control simulation. Journal of Applied Research and Technology, 3, 3, (2005), 222-237.

L., C., G., Souza, Dynamics and Robust Control for Uncertain Flexible Space System, PhD Thesis, Cranfield Institute of Technology, CoA, Cranfield, England, 1992.

L., C., G., Souza, Robust controllers design for flexible space system using a combination of LQG/LTR and PRLQG methods. In: Dynamics and Control of Structure in Space III. U.K.: C. L. Kirk and D. J. Inman, (1996), 151-166.

M., H., Kaplam, Modern Spacecraft Dynamics and Control, John Wiley \& Sons New Your, 1976.

M., M., Berry, B., J., Naasz, H., Y., Kim, C., D., Hall, Integrated Orbit and Attitude Control for a Nano Satellite with Power Constrains. AAS/AIAA Space Flight Mechanical Conference. P. Rico, February, 9-12, 2003.

O., Holub, Development for VLT Telescope Controller Design. PhD thesis, Katedra Rídicí Techniky, 2005.

P., Tsiotras et al, A Spacecraft Simulator for Research and Education. Paper of Georgia Institute of Technology, EUA, 2007.

Quanser homepage. At: <http://www.quanser.com/>.

R., G., Gonzales, L., C., G., Souza, Application of the SDRE method to design a control system simulator. Advances in Astronautical Sciences. 134, (2009), 2251-2258.

R., H., Cannon, D., E., Rosenthal, Experiments in control of flexible structures with noncolocated sensors and actuators. Journal of Guidance. AIAA, 7,5 , (1984), 546-553.

S., Skogestad, I., Postlethwaite, Multivariable Feedback Control Analysis and Design. 2. Ed. Chichester, England: John Wiley \& Sons, 2005. 